\title{
Metabolic and respiratory adaptations during intense exercise following long-sprint training of short duration
}

\author{
Claire Thomas · Olivier Bernard · Carina Enea · \\ Chadi Jalab · Christine Hanon
}

Received: 12 November 2010/ Accepted: 21 May 2011/Published online: 9 June 2011

(C) Springer-Verlag 2011

Abstract This study aimed to determine metabolic and respiratory adaptations during intense exercise and improvement of long-sprint performance following six sessions of long-sprint training. Nine subjects performed before and after training (1) a 300-m test, (2) an incremental exercise up to exhaustion to determine the velocity associated with maximal oxygen uptake $\left(v-V \mathrm{O}_{2 \max }\right)$, (3) a 70 -s constant exercise at intensity halfway between the $v-V \mathrm{O}_{2 \max }$ and the velocity performed during the $300-\mathrm{m}$ test, followed by a 60-min passive recovery to determine an individual blood lactate recovery curve fitted to the bi-exponential time function: Laðt $\mathrm{P} 1 / 4 \mathrm{La} 00 \mathrm{Pp} A_{1} \circlearrowright 1-\mathrm{e}^{-c_{1}} \mathrm{P} \mathrm{p} A_{2} \circlearrowright 1-\mathrm{e}^{-\mathrm{c}_{2}} \mathrm{P}$, and blood metabolic and gas exchange responses. The training program consisted of 3-6 repetitions of 150-250 m interspersed with rest periods with a duration ratio superior or equal to 1:10, 3 days a week, for 2 weeks. After sprint training, reduced metabolic disturbances, characterized by a lower peak expired ventilation and carbon dioxide output, in

Communicated by Jean-René Lacour.

\section{Thomas $(\&) \cdot$ C. Hanon}

Laboratoire de Biomécanique et de Physiologie,

Mission Recherche, Institut National des Sports et de l'Education Physique (INSEP), 11 avenue du Tremblay, 75012 Paris, France e-mail: claire.thomas@univ-evry.fr

\section{Thomas}

Département des Sciences et Techniques des Activités Physiques et Sportives, UFR Sciences fondamentales et appliquées, Université Evry Val d'Essonne, Bvd F. Mitterrand,

91025 Evry Cedex, France

O. Bernard · C. Enea $\cdot$ C. Jalab

Laboratoire des Adaptations Physiologiques aux Activités Physiques EA 3813, Faculté des Sciences du Sport, Université de Poitiers, 4 allée Jean Monnet, 86000 Poitiers, France addition to a reduced peak lactate ( $P$ W 0.05), was observed. Training also induced significant decrease in the net amount of lactate released at the beginning of recovery $(P W 0.05)$, and significant decrease in the net lactate release rate $(\mathrm{NLRR})(P W 0.05)$. Lastly, a significant improvement of the 300-m performance was observed after training. These results suggest that long-sprint training of short durations was effective to rapidly prevent metabolic disturbances, with alterations in lactate accumulation and gas exchange, and improvement of the NLRR. Furthermore, only six longsprint training sessions allow long-sprint performance improvement in active subjects.

Keywords Constant exercise $\cdot$ Sprint $\cdot$ Proton $\cdot$ Lactate exchange $\cdot$ Lactate kinetics $\cdot$ High-intensity exercise

\section{Introduction}

During heavy exercise, the rapid increase in energy demand of contracting skeletal muscle is associated with the production and accumulation of lactate and proton ions. Lactate and protons are subsequently removed by various intracellular mechanisms, or are released to the blood and removed by other cells according to the lactate shuttle (Brooks 2000). Blood lactate kinetics during recovery can be investigated by means of a bicompartimental model of the lactate distribution space (Freund and Zouloumian 1981a). It has been shown that the two exponential terms that describe the time course of blood lactate concentrations (Freund and Gendry 1978) provide indirect information on the abilities to exchange and remove lactate during recovery (Freund and Zouloumian 1981a). The velocity constants of these functions are indicators of the blood lactate recovery kinetics, because they specifically 
reflect the abilities to exchange lactate between the previously worked muscle and the blood [high velocity constant $\left(c_{1}\right)$, and to remove it from the total lactate diffusion space [low velocity constant $\left(\mathrm{c}_{2}\right)$ ] (Freund and Zouloumian 1981a).

Endurance training improves the lactate exchange ability $c_{1}$ (Messonnier et al. 2001). Besides, lactate exchange ability has been reported to be higher in middle-distance runners than in sprint runners (Bret et al. 2003), and was correlated with the best performance over a $800 \mathrm{~m}$ (Bret et al. 2003). Endurance training also improves the lactate removal ability $c_{2}$ from the blood (Messonnier et al. 2001, 2006), while $c_{2}$ did not differ between sprint and endurance runners after 1-min of constant high-intensity exercise (Bret et al. 2003). Interestingly, $c_{2}$ was related to sarcolemmal lactate-proton cotransporter (MCT1 and MCT4) contents (Thomas et al. 2005) and maximal oxidative capacity in humans (Thomas et al. 2004).

With sprint training, many adaptations occur in gas exchange across the lungs and within skeletal muscles. During matched work exercise, a reduced respiratory response has been reported after sprint training (Harmer et al. 2000), whereas during exercise performed until exhaustion, a greater pulmonary $\mathrm{CO}_{2}$ output was observed (McKenna et al. 1997), which may improve acid-base control after sprint training and allow improvement in the ability to perform high-intensity exercise (McKenna et al. 1997). Furthermore, muscle oxidative potential (Burgomaster et al. 2005, 2007; Parra et al. 2000; Rodas et al. 2000) and sarcolemmal lactate-proton cotransporter isoforms (Burgomaster et al. 2007) have been reported to be rapidly altered after 1 week of sprint interval training, which suggests that improvements in lactate and $\mathrm{H}^{\text {? }}$ metabolism and transport could be rapidly stimulated by repeated bouts of very intense sprint exercise (Bret et al. 2003). To our knowledge, no data are available on the effects of long-sprints training of short duration on lactate and acid-base balance regulation during and after supramaximal exercise.

In consequence, we hypothesized that lactate exchange and removal abilities could be enhanced in response to exercise at the same absolute workload after just 2 weeks of long-sprint training. Then, this could therefore result in reductions in blood lactate and proton accumulations, associated with adaptations in gas exchange for the regulation of $\mathrm{pH}$. In an attempt to verify these hypotheses, we investigated the effects of six sessions of long-sprint training on (1) metabolic disturbances and (2) the lactate recovery kinetics and its associated parameters, both in response to a 70-s supramaximal exercise conducted at an identical power output before and after training. In order to investigate these adaptations, we voluntarily chose a constant velocity test (CET) at an intensity which challenged anaerobic and aerobic metabolism inducing marked metabolic changes.

\section{Methods}

Subjects

Nine male volunteers [(mean \pm SE), age $20.9 \pm 0.7$ years, height $175.0 \pm 2.0 \mathrm{~cm}$ and body mass $70.6 \pm 3.7 \mathrm{~kg}]$ participated in this study. All of them were well-trained sport students regularly involved in running or in team sports (3-5 training sessions a week). All the participants were notified of the research procedures, requirements, benefits, and risks before providing informed consent. The study was approved by the Institutional Research Ethics Committee and conformed to the Declaration of Helsinki regarding the use of human subjects.

\section{Experimental design}

The protocol included pre-training, training, and posttraining sessions, and was realized before the summer competition period. In pre- and post-training, subjects performed two track-running session tests. All tests were performed in late afternoon at least $4 \mathrm{~h}$ after the last meal. During the first visit, subjects performed a 300-m maximal sprint on the outdoor track. Then, the second test was an incremental test aiming to determine individual maximal oxygen consumption and the minimal speed associated with $V \mathrm{O}_{2 \max }\left(v-V \mathrm{O}_{2 \max }\right)$, and was followed $1 \mathrm{~h}$ later, by a maximal 70-s constant test.

For the second session of tests, oxygen uptake $\left(\mathrm{VO}_{2}\right)$, carbon dioxide production $\left(\mathrm{VCO}_{2}\right)$, and minute ventilation (VE) were measured breath by breath by means of an open circuit metabolic cart (Metamax 3B, CORTEX, Germany). Heart rate (HR) was measured and recorded continuously with a HR monitor (S810i and T61 electrode belt, Polar Electro, Kempele, Finland). Over all the test sessions, arterialised capillary fingertip blood samples $(85 \mathrm{lL})$ were taken in order to measure $\mathrm{pH}$, partial pressure of carbon dioxide $\left(\mathrm{PCO}_{2}\right)$, blood lactate and bicarbonate concentration ([Lact] and $\left[\mathrm{HCO}_{3}{ }^{-}\right]$, respectively) with an i-STAT dry chemistry analyser (Abbott, Les Ulis, France). These measurements with the i-STAT portable analyser have been found to be reliable (ICC $=0.77-0.95$ following maximal exercise) (Dascombe et al. 2007). In order to measure the blood lactate kinetics following 70-s constant exercise and because of the limited range of the i-STAT system (0.30-20 mmol L ${ }^{-1}$ ), additional samples $(20 \mathrm{lL})$ were taken in other fingertips for analysis using a Biosen Lactate analyser (Biosen C-line analyser, EKF Industrie, Elektronik $\mathrm{GmbH}$, Barleben, Germany) (Davison et al. 2000). 
Protocol

Supramaximal exercise: $300 \mathrm{~m}$

The warm-up was standardised according to a regular preevent competition warm-up (15 min of jogging, stretching, warm-up short sprints). Then, subjects performed the 300-m test. They were asked to run as fast as possible during the race, and strong vocal support was given from the start to the finish line. The performance was recorded with a stopwatch by a coach specialised in track and field.

Assessment of maximal oxygen uptake $\left(V_{2 \max }\right)$

and $v-V O_{2 \max }$

$V \mathrm{O}_{2}$ and $v-V \mathrm{O}_{2 \max }$ were determined using an incremental test conducted on a 333-m indoor track marked every $25 \mathrm{~m}$. The running pace was given by sounds emitted through a speaker controlled by a computer software program to ensure precise control of speed by setting an audible cadence. The initial velocity was $10 \mathrm{~km} \mathrm{~h}^{-1}$, which was then increased by $1 \mathrm{~km} \mathrm{~h}^{-1}$ every min until exhaustion. Lactate concentrations were determined at rest and immediately after the end of the $V \mathrm{O}_{2 \max }$ test.

\section{0-s constant test delta50}

This test was performed on the same 333-m indoor track as the $V \mathrm{O}_{2 \max }$ test, and the subject had to attain a constant velocity halfway between the $v-V \mathrm{O}_{2 \max }$ and the velocity performed during the $300-\mathrm{m}$ test $(50 \% \mathrm{D})$. This constant velocity was identical in pre and post-training tests. An audio signal-generator (laboratory homemade) was programmed to produce individualized signals at each $25-\mathrm{m}$ interval (Hanon et al. 2010), and the athlete was accompanied by a researcher on a bike who gave the velocity to perform and verbal encouragement throughout the test period. In addition, strong verbal encouragements were provided throughout the test by other researchers.

$1 \mathrm{~h}$ after the $V \mathrm{O}_{2 \max }$ test, subjects performed the 70 -s test. Blood samples were taken before the test at rest, and 1 and $7 \mathrm{~min}$ from the onset of passive recovery for the determination of the blood acid-base status, at rest, and at $1,2,3,4,5,6,7,8,9,10,12,15,20,30,40,50$, and $60 \mathrm{~min}$ of recovery from the 70 -s constant test for the determination of blood lactate concentrations.

\section{Training protocol}

Training consisted of six long sprint training sessions [2 9 (3 $9150 \mathrm{~m}), 29$ (150-200-150 m), $39250 \mathrm{~m}$, $69150 \mathrm{~m}, 49200 \mathrm{~m}, 39250 \mathrm{~m}$ )] interspersed with rest periods with a duration ratio superior or equal to $1: 10$ (exercise:recovery). 1-3 days were permitted between training sessions. Post-tests for $V_{2} O_{2 \max }$ and the constant exercise tests were performed 5 days after the end of the training sessions, and the 300-m performance test was conducted 8 days after, respectively.

The choice of the content of each training session was based on textbooks of training (Newsholme et al. 1994), which present interval sprint training with long recoveries (with an exercise/recovery ratio superior or equal to $1: 10$ ) for the enhancement of long-sprint performance, and commonly used in athletic training at the difference of laboratory training sessions consisting of repeated 30-s allout exercise (Burgomaster et al. 2005). Furthermore, subjects rested 1-3 days between training sessions and 57 days after the training program, in an effort to promote recovery and facilitate performance adaptations, since it has been reported that tapering allows metabolic overcompensation and performance improvement after training regimen (Shepley et al. 1992).

Blood samples

\section{Lactate kinetics analysis}

Arterialized blood lactate was collected during the recovery periods following the supramaximal exercise test and each individual curve was fitted using the following biexponential equation (Freund and Gendry 1978):

$\mathrm{La} \partial \mathrm{P} 1 / 4 \mathrm{La} 00 \mathrm{Pp} A_{1} \circlearrowright 1-\mathrm{e}^{-\mathrm{c}_{1}} \mathrm{P} \mathrm{p} A_{2} \partial 1-\mathrm{e}^{-\mathrm{c}_{2}} \mathrm{P}^{t}$

where $\mathrm{La}(t)$ is the measured lactate concentration in arterialized blood at time $t$ after the end of exercise and at the beginning of the recovery; $A_{1}$ and $A_{2}\left(\mathrm{mmol} \mathrm{L}^{-1}\right)$ are the amplitudes of the two exponential components, and $\mathrm{c}_{1}$ and $c_{2}\left(\mathrm{~min}^{-1}\right)$ are their respective velocity constants. The individual parameters of the bi-exponential function were fitted by means of an iterative nonlinear technique, using DataFit 6.0 software to determine the values of $A_{1}, A_{2}, c_{1}$, $\mathrm{C}_{2}$ and $\mathrm{La}(0)$. The percentage of the variance explained by the use of the bi-exponential curve fit was determined by correlation of the observed and the predicted $\mathrm{La}(t)$ at each time and by squaring of the Pearson-product correlation coefficient (Fig. 1).

Applications of the parameters of the fits to Eq. 1 to a two-compartment model of the lactate distribution space allows prediction of the evolution of the net lactate release rate (NLRR, mmol $\mathrm{min}^{-1}$ ) during the recovery by means of the following equation

$$
\begin{gathered}
\text { NLRRðt } \mathrm{P} 1 / 4 \partial_{\mathrm{c}_{1}}-d_{2} \mathrm{P} \times V_{\mathrm{S}} \times A_{1} \times \mathrm{e}^{-\mathrm{c}_{1}{ }^{t}} \mathrm{p} \partial \mathrm{c}_{2}-d_{2} \mathrm{P} \\
\times V_{\mathrm{S}} \times A_{2} \times \mathrm{e}^{-\mathrm{c}_{2}{ }^{t}} \mathrm{p} 1
\end{gathered}
$$

where $V_{\mathrm{S}}$ is the volume of the compartment that represents the difference between the total lactate distribution space 
Fig. 1 Time courses of arterialized blood lactate concentrations during recovery from 70-s constant exercise test before (open symbols) and after (closed symbols) six sessions of sprint training. Blood lactate concentrations are significantly lower ( $P W 0.05$ ) post- than pretraining from the $3 \mathrm{rd}$ min of the onset of recovery up to the 7 th min of recovery

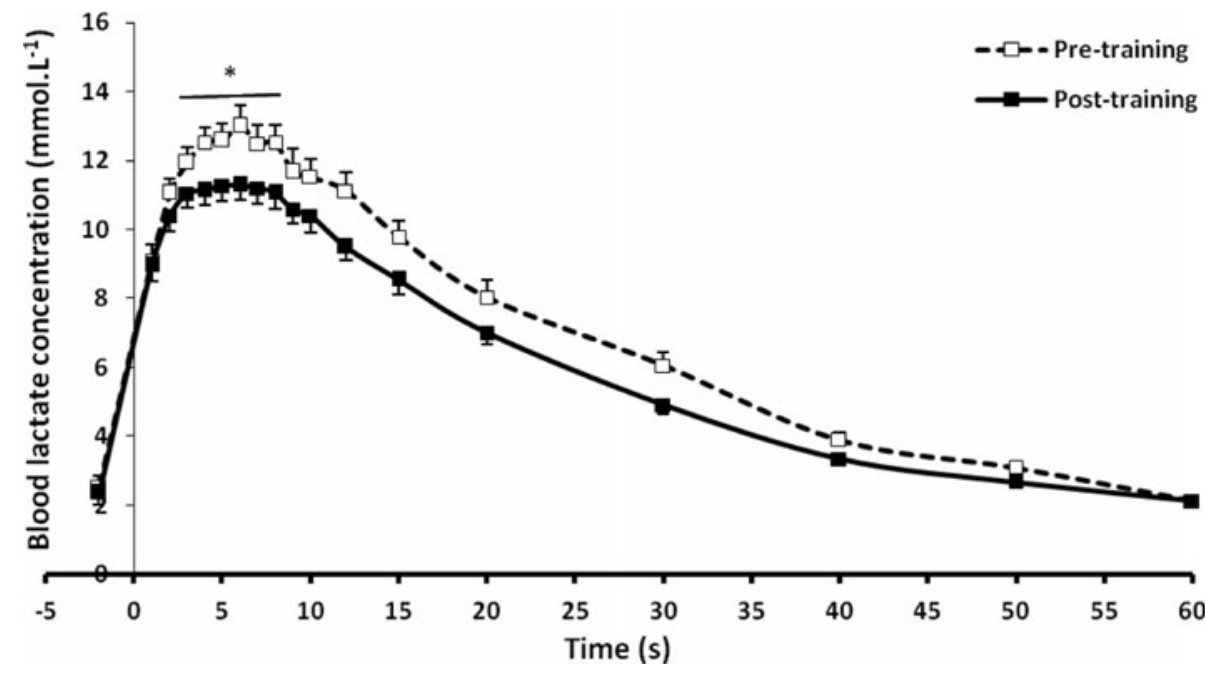

Metabolic disturbances

( $\left.V_{\text {TLS }}\right)$ and the volume of muscles involved in the previous exercise $\left(V_{\mathrm{M}}\right)$, i.e. $V_{\mathrm{S}}=V_{\mathrm{TLS}}-V_{\mathrm{M}}=250 \mathrm{~mL} \mathrm{~kg}^{-1}$ body mass, and 1 is the basal lactate release rate to the blood,i.e. $0.12 \mathrm{mmol} \mathrm{min}^{-1}$. Application of the model gives realistic predictions when the difference between $\mathrm{d}_{2}$ and $\mathrm{c}_{2}$ is small, i.e. $d_{2}=c_{2}-0.005 \mathrm{~min}^{-1}$. The integral of Eq. 2 gives an estimation of the net amount of lactate released (NALR, $\mathrm{mmol}$ ) from the previously active muscles to the blood (for further details of the model and its application, see Bret et al. 2003; Freund and Zouloumian 1981b).

\section{Statistics}

Descriptive statistics are expressed as mean \pm SE. Differences in pre- and post-training were identified by means of the paired Student's $t$ test or Wilcoxon-signed rank test depending on the normality, using Sigmatstat3.1 software. Differences between pre- and post-training values and relationships among variables were considered to be significant for $P W 0.05$ and to represent a tendency for 0.05 W $P$ B 0.10 . NS indicated no significant difference.

\section{Results}

\section{Incremental test}

Mean values obtained in the incremental test are presented in Table $1 . V \mathrm{O}_{2 \max }$ was significantly improved $(P W 0.05)$ with training, but no significant differences were observed for $v-V \mathrm{O}_{2 \max }$ after training (NS).

70-s constant supramaximal test

The velocity at $50 \% \mathrm{D}$ between velocity of $300-\mathrm{m}$ test and $v-V \mathrm{O}_{2 \max }$ was $21.1 \pm 0.3 \mathrm{~km} \mathrm{~h}^{-1}$.
Blood lactate concentration at $1 \mathrm{~min}$ of recovery following 70 -s constant exercise did not change after training $\left(9.1 \pm 0.6\right.$ vs. $9.0 \pm 0.6 \mathrm{mmol} \mathrm{L}^{-1}$, NS), whereas peak blood lactate concentrations was $13.2 \pm 0.6 \mathrm{mmol} \mathrm{L}^{-1}$ in pre-training and significantly decreased at $11.4 \pm 0.6$ mmol L ${ }^{-1}$ in post-training $(P W 0.05)$ (Table 2$)$.

As reported in Table 3 , mean blood $\mathrm{pH}$ values at min 1 and 7 of recovery did not change significantly after training, although intra-individual changes in $\mathrm{pH}$ after training were related to changes in [Lact] $(r=-0.84, P W 0.01)$. $\mathrm{VE}_{\text {peak }}$ during constant exercise and the drop in $\mathrm{PCO}_{2}$ at min 7 of recovery were significantly lower after training $(P W 0.05)$. In consequence, $V C_{2 \text { peak }}$ was significantly lower during constant exercise after training $(P W 0.05)$, and the drop in blood $\left[\mathrm{HCO}_{3}^{-}\right]$tended to be lower at $\min 7$ of recovery after training $(P=0.08)$.

As expected, overall the intra-individual change between pre and post training in $\mathrm{pH}$ value into $7 \mathrm{~min}$ was negatively related to the decrease in $V \mathrm{CO}_{\text {2peak }}$ and $\mathrm{VE}_{\text {peak }}$ after training $(r=-0.86, P W 0.01$ and $r=-0.68, P=0.06$, respectively), and to the increase in $\left[\mathrm{HCO}_{3}{ }^{-}\right]$into $7 \mathrm{~min}$ of recovery $(r=0.90, P W 0.01)$. Furthermore, after sprint training, changes in $V \mathrm{CO}_{2 \text { peak }}$ and $\mathrm{VE}_{\text {peak }}$ were significantly correlated ( $r=0.89, P W 0.01)$. These changes were significantly correlated to the training-induced increase in $\left[\mathrm{HCO}_{3}{ }^{-}\right]$at $7 \mathrm{~min}$ after constant exercise $(r=-0.86$, $P W 0.01$ and $r=-0.81, P W 0.05$, respectively).

At last, as shown in Table 4 , no change in $V \mathrm{O}_{2 \text { peak }}$ was reported after training $(97.0 \pm 4.9$ vs. $96.6 \pm 6.0 \%$ of $V \mathrm{O}_{2 \max }, \mathrm{NS}$ ),

\section{Descriptive data of the blood lactate recovery curves}

The time course of blood lactate concentration during recovery showed the classic biphasic evolution pattern for 
Table 1 Parameters measured at the end of incremental test (mean \pm SE)

\begin{tabular}{lllll}
\hline & $V \mathrm{O}_{2 \max }\left(\mathrm{ml} \mathrm{min}^{-1} \mathrm{~kg}^{-1}\right)$ & Respiratory exchange ratio & {$\left[\right.$ Lact] $\left(\mathrm{mmol} \mathrm{l}^{-1}\right)$} & $v-V \mathrm{O}_{2 \mathrm{max}}\left(\mathrm{km} \mathrm{h}^{-1}\right)$ \\
\hline Pre-training & $56.4 \pm 1.2$ & $1.18 \pm 0.02$ & $11.7 \pm 0.5$ & $16.8 \pm 0.3$ \\
Post-training & $57.8 \pm 1.4^{*}$ & $1.18 \pm 0.01$ & $12.1 \pm 0.3$ & $17.1 \pm 0.4$
\end{tabular}

$\mathrm{VO}_{2 \max }$ maximal oxygen consumption, $\mathrm{VCO}_{2} / \mathrm{VO}_{2}$ ratio respiratory exchange ratio, [Lact] lactate concentration at the end of the test, $v$ - $\mathrm{VO}_{2 m a x}$ minimal speed at which the athlete was running when $\mathrm{KO}_{2}$ max occurred

Table 2 Mean blood lactate concentration characteristic, and parameters of the net lactate release rate and the net amount of lactate release during recovery of 70-s constant exercise test (mean $\pm \mathrm{SE}$ )

\begin{tabular}{lllll}
\hline & {$[\mathrm{La}(0)]\left(\mathrm{mmol} \cdot \mathrm{L}^{-1}\right)$} & {$[\mathrm{LaMax}]\left(\mathrm{mmol} \cdot \mathrm{L}^{-1}\right)$} & $\mathrm{NLRR}(0)\left(\mathrm{mmol} \cdot \mathrm{min}^{-1}\right)$ & $\mathrm{NALR}(10)(\mathrm{mmol})$ \\
\hline Pre-training & $6.6 \pm 0.8$ & $13.2 \pm 0.6$ & $78.2 \pm 17.4$ & $195.3 \pm 25.3$ \\
Post-training & $7.4 \pm 0.7$ & $11.4 \pm 0.6^{*}$ & $47.5 \pm 2.6^{*}$ & $162.3 \pm 11.3^{*}$
\end{tabular}

$[\mathrm{La}(0)]$, which corresponds to lactate concentration at the end of exercise, derived from the mathematical model

* $P$ W0.05 significantly different from pre-training

Table 3 Metabolic and gas exchange parameters measured at rest and during the recovery of the 70-s constant exercise test (mean \pm SE)

\begin{tabular}{llllll}
\hline & Time & {$[\mathrm{Lact}] \mathrm{mmol} \mathrm{L}^{-1}$} & $\mathrm{pH}$ & {$\left[\mathrm{HCO}_{3}^{-}\right] \mathrm{mmol} \mathrm{L}^{-1}$} & $P C \mathrm{CO}_{2}(\mathrm{mmHg})$ \\
\hline Pre-training & Rest & $2.5 \pm 0.3$ & $7.42 \pm 0.01$ & $24.8 \pm 0.6$ & $38.3 \pm 0.9$ \\
Post-training & Rest & $2.3 \pm 0.4$ & $7.42 \pm 0.01$ & $24.9 \pm 0.3$ & $38.9 \pm 0.9$ \\
Pre-training & $1 \mathrm{~min}$ & $9.4 \pm 0.5^{\$ \$ \$}$ & $7.23 \pm 0.01^{\$ \$ \$}$ & $15.9 \pm 0.4^{\$ \$ \$}$ & $37.3 \pm 0.9$ \\
Post-training & $1 \mathrm{~min}$ & $8.7 \pm 0.5^{\$ \$}$ & $7.24 \pm 0.01^{\$ \$ \$}$ & $16.7 \pm 0.6^{\$ \$ \$}$ & $38.6 \pm 1.2$ \\
Pre-training & $7 \mathrm{~min}$ & $12.6 \pm 0.6^{\$ \$, \mathrm{tt}}$ & $7.22 \pm 0.02^{\$ \$}$ & $12.3 \pm 0.7^{\$ \$, \mathrm{ttt}}$ & $29.8 \pm 1.1^{\$ \$ \$}$ \\
Post-training & $7 \mathrm{~min}$ & $11.3 \pm 0.4^{* \$ \$ \$, \mathrm{t}}$ & $7.23 \pm 0.01^{\$ \$ \$}$ & $13.9 \pm 0.5^{\$ \$, \mathrm{t}}$ & $32.9 \pm 0.8^{*} \$ \$ \$$ \\
\hline
\end{tabular}

$P=0.08$ for $\left[\mathrm{HCO}_{3}^{-}\right]$between pre- and post-training value int $\mathrm{o} 7 \mathrm{~min}$ of recovery

[Lact] blood lactate concentration, $\left[\mathrm{HCO}_{3}^{-}\right]$blood bicarbonate concentration, $\mathrm{PCO}_{2}$ partial pressure of carbon dioxide

$\$ P W 0.05 ;{ }^{\$} \$ P W 0.001$ significantly different from rest

${ }^{\mathrm{t}} P W 0.05,{ }^{\mathrm{tt}} P \mathrm{~W} 0.01 ;{ }^{\mathrm{ttt}} P W 0.001$ significantly different from $1 \mathrm{~min}$ of recovery

* $P$ W 0.05 significantly different from pre-training

Table 4 Gas exchange parameters measured during the constant exercise test (mean \pm SE)

\begin{tabular}{llll}
\hline & $V \mathrm{O}_{2 \text { peak }}\left(\mathrm{L} \min ^{-1}\right)$ & $\left.V \mathrm{VO}_{\text {2peak }}(\mathrm{L} \mathrm{min})^{-1}\right)$ & $\left.\mathrm{VE}_{\text {peak }}(\mathrm{L} \mathrm{min})^{-1}\right)$ \\
\hline Pre-training & $3.8 \pm 0.2$ & $4.6 \pm 0.2$ & $128.6 \pm 5.4$ \\
Post-training & $3.7 \pm 0.2$ & $4.3 \pm 0.2^{*}$ & $117.5 \pm 3.6^{*}$ \\
\hline
\end{tabular}

$V O_{2 p e a k}$ peak of oxygen uptake reached during the constant exercise test, $V C O_{2 p e a k}$ peak of carbon dioxide production reached during the constant exercise test, $V E_{\text {peak }}$ peak of minute ventilation reached during the constant exercise test

* $P W 0.05$ significantly different from pre-training

Table 5 Parameters of the bi-exponential curves fitted to arterialized blood lactate resting value and recovery curves obtained from 70 -s constant exercise test (mean $\pm \mathrm{SE})$

\begin{tabular}{lllll}
\hline & $A_{1}\left(\mathrm{mmol} \mathrm{L}^{-1}\right)$ & $\mathrm{c}_{1}\left(\mathrm{~min}^{-1}\right)$ & $A_{2}\left(\mathrm{mmol} \mathrm{L}^{-1}\right)$ & $\mathrm{c}_{2}\left(\mathrm{~min}^{-1}\right)$ \\
\hline Pre-training & $16.1 \pm 2.7$ & $0.357 \pm 0.054$ & $-21.7 \pm 3.08$ & $0.055 \pm 0.008$ \\
Post-training & $12.3 \pm 1.6$ & $0.311 \pm 0.043$ & $-18.2 \pm 1.91$ & $0.060 \pm 0.006$ \\
\hline
\end{tabular}

$A_{1}, \mathrm{c}_{1}, A_{2}, \mathrm{c}_{2}$ refer to the definition of Eq. 1 in lactate kinetics analysis

all subjects. From the end of exercise, blood lactate concentration increased, reached a peak, and thereafter decreased progressively. The bi-exponential model accurately fitted the individual recovery curves obtained after the constant exercise test. Values are reported in Tables 2 and 5. In most cases, the bi-exponential equation 
accounted for more than $98 \%$ of the variance in the lactate recovery curves. In addition, the fit accuracy for all subjects was comparable to that obtained previously (Thomas et al. 2004).

Velocities constant measured during 70-s constant exercise recovery

No significant change in $c_{1}$ and $c_{2}$ were observed after long-sprint training of short-duration (Table 5), although intra-individual changes are observed.

\section{NLRR and net amount of lactate released estimated} during 70-s constant exercise recovery

After sprint training, as indicated in Table 2, NLRR(0) significantly decreased ( $P W 0.05$, Fig. 2a), and the NALR value at $10 \mathrm{~min}$ of recovery was lower by $25 \%(P W 0.05$, Fig. 2b). In response to the training regimen protocol, the decrease in NALR(10) after the constant exercise was significantly related to changes in maximal [Lact] ( $r=0.78, P W 0.05)$.

Supramaximal exercises

The 300-m performance was significantly improved after 2 weeks of sprint training $(42.77 \pm 0.67 \mathrm{vs} .41 .77 \pm 0.64 \mathrm{~s}$, $P W 0.05)$, and the post-training chronometric values corresponded to $97.7 \pm 4.2 \%$ of the pre-training $300-\mathrm{m}$ performance. The training-induced improvements of $300-\mathrm{m}$ velocity were inversely related to the changes in $c_{2}(r=0.70$, $P W 0.05$ ), but were not related to any other parameters (NS).

\section{Discussion}

The results of the present study demonstrated that longsprint protocols performed three times per week over as
Fig. 2 a Mean $( \pm$ SE) net lactate release rate (NLRR) during recovery from 70 -s constant exercise test before (dotted line) and after (full line) six sessions of sprint training. Significant difference $(P W 0.05)$ between pre- and post-training at 0,1 and $2 \mathrm{~min}$ of recovery. $b$ Mean $( \pm S E)$ net amount of lactate release (NALR) during recovery from 70-s constant exercise test before (dotted line) and after (full line) six sessions of sprint training. Significant difference $(P W 0.05)$ between pre- and post-training from 1 to $10 \mathrm{~min}$ of recovery
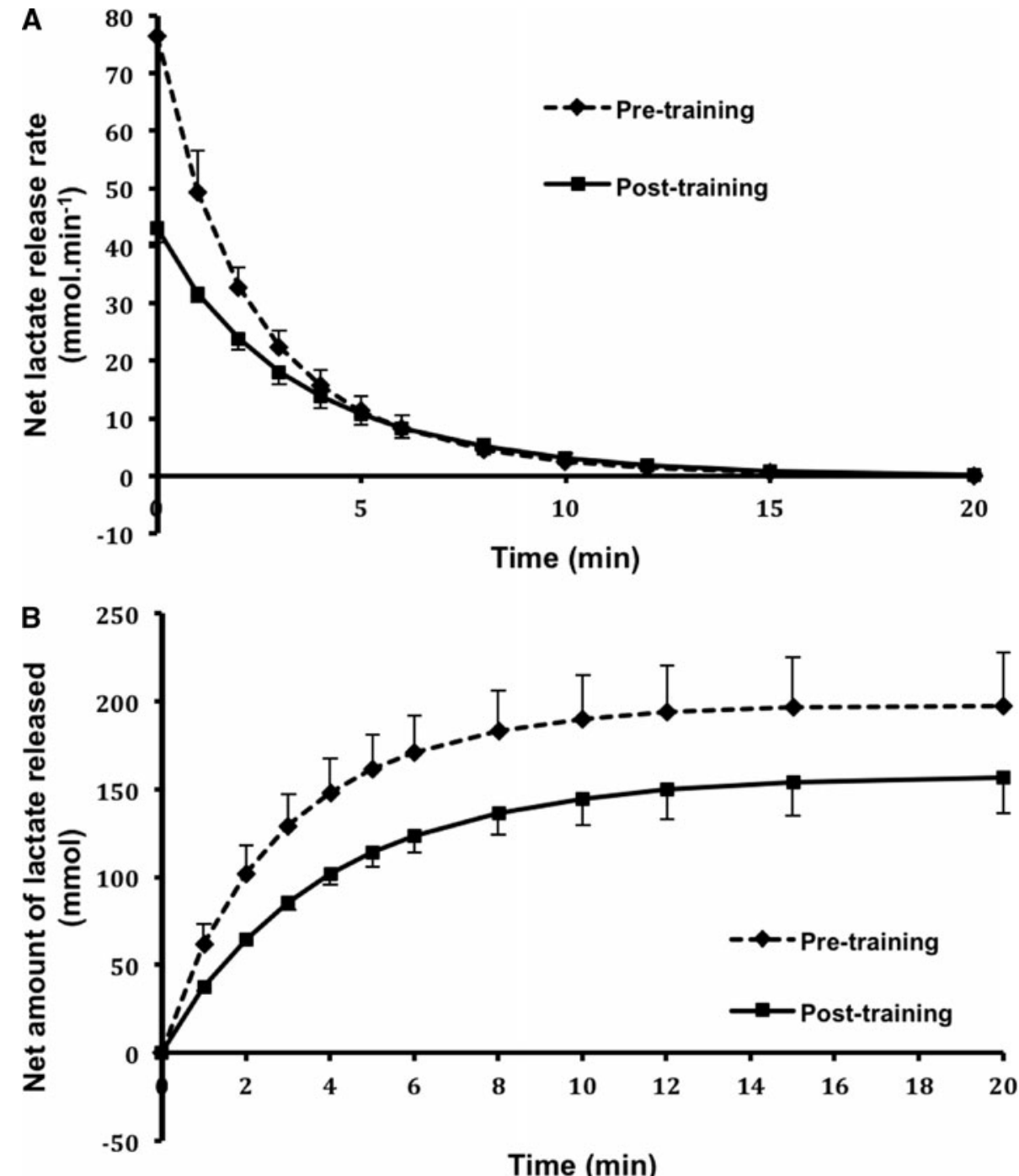
brief a period of time as 2 weeks could lead to a significant reduced metabolic disturbances, since we observed significant lower peak expired ventilation and carbon dioxide output during intense exercise after training, in addition to a significant reduced peak blood lactate concentration and a trend to a higher blood bicarbonate concentration during recovery. We also observed decreases in the NLRR at $t=0$ min of recovery (NLRR $(0))$ and in the net amount of lactate released at $t=10 \mathrm{~min}(\mathrm{NALR}(10))$ after the constant exercise test. In addition, decrease in maximal [Lact] after sprint training was related to the training-induced decrease in NALR(10) and increase in blood $\mathrm{pH}$ during recovery. Finally, a significant improvement of 300-m test performance was observed, which was related to intraindividual alterations in blood lactate removal $\left(\mathrm{c}_{2}\right)$ ability.

In the present study, significant reductions in $\mathrm{VE}_{\text {peak }}$ and $V \mathrm{CO}_{2 \text { peak }}$ were observed during the constant exercise test after long-sprint training, that confirms previous results obtained during matched work-exercise before and after sprint training (Harmer et al. 2000). Changes in respiratory parameters after sprint training are also in accordance with previous results (McKenna et al. 1997), which showed greater pulmonary and active skeletal muscle gas exchange during maximal 30-s sprint exercise performed until exhaustion. Although we could not determine the lowest $\mathrm{pH}$ values, individual changes in $\mathrm{pH}$ value at $7 \mathrm{~min}$ into recovery after sprint training contribute to the decrease in $\mathrm{VE}_{\text {peak }}$ and $V \mathrm{CO}_{2 \text { peak }}$, which confirms previous results (Nielsen et al. 2002; Peronnet et al. 2007). Based on lower peak $\mathrm{VE}$ and $V \mathrm{CO}_{2}$, sprint training could also reduce the respiratory muscle work and $\mathrm{VO}_{2}$ (Aaron et al. 1992), thus allowing increased exercising leg muscle $V \mathrm{O}_{2}$ without any change in the whole body $V \mathrm{O}_{2}$, as previously observed after sprint training by Harmer et al. (2000). In this line, the rise in pulmonary ventilation during long sprints such as 300 and $400 \mathrm{~m}$ (Hanon et al. 2010), could result from the role of $\mathrm{pH}$ for ventilatory control (Nielsen et al. 2002) and could be affected by the sprint-training effects of lower respiratory muscle $V \mathrm{O}_{2}$ on locomotor muscle $V \mathrm{O}_{2}$ contribution, which could contribute to long-sprint performance improvement.

Furthermore, as $V \mathrm{O}_{2 \text { peak }}$ was the same after sprint training, aerobic ATP yield should be similar, whereas glycolytic ATP yield was presumably lower as suggest by the lower lactate peak value. In consequence, this suggests that mechanical efficiency was increased after training in these active subjects during the constant exercise test, which could also contribute to higher performance improvement in 300-m tests. In addition, as intra-individual improvement in the 300-m performance was related to intra-individual changes in blood lactate removal ability, we could hypothesize that lower fatigue during these longsprints could result from lactate shuttle adaptations
(Messonnier et al. 2007; Thomas et al. 2005) and blood acid-base regulation (McKenna et al. 1997), since it has been reported that lactate and protons could play a role in the appearance of fatigue (Favero et al. 1995; Spriet et al. 1985).

Interestingly, lower peak [Lact] and NALR(10) observed after short-sprint training in response to an exercise bout similar in terms of absolute work rate and duration seem to be due to a lower lactate appearance in the bloodstream during the early phase of the recovery. This lower appearance was not related to an improvement in blood lactate removal ability, since $c_{2}$ does not change after sprint training, but may be related to a slower rate of lactate release at the onset of the recovery than before sprint training. In accordance, NLRR(0) was lower after training. Because $c_{1}$, which represents the lactate exchange ability during the recovery, was not altered by training, the lowest NLRR(0) maybe be the result of a lower muscle to blood gradient that will result in a lower amount of lactate released during the recovery. In line with this, NALR(10) was significantly lower after training. Furthermore, the lower peak [Lact] value during the recovery after training, associated with lacks of changes in $c_{1}$ and $c_{2}$ due to the training regimen, may argue in favor of a lower muscle lactate accumulation after training.

In consequence, these results could be explained by an alteration in glycolytic flux. Indeed, although some have not (Dawson et al. 1998; Hickson et al. 1976), different studies have reported that glycolytic flux is more precisely regulated after sprint training (Cadefau et al. 1990; Fournier et al. 1982; Roberts et al. 1982), which may be responsible for superior maximal exercise performance in sprint-trained athletes compared with other athletes (Costill et al. 1976) and for 300-m performance improvement observed in this study. Here, for the exercise performed at the same absolute work rate, we can speculate that a lower rate of glycolytic enzyme activity after long-sprint training could explain the reduction of muscle pyruvate accumulation and lactate formation. In addition, by facilitating intramuscular lactate exchange and oxidation, mitochondrial lactate-proton cotransporters 1 (MCT1) could depress net muscle lactate release, as previously observed (Dubouchaud et al. 2000), and increase in sarcolemmal MCTs content could improve lactate exchange between muscle fibers (Brooks 2000, 2002), allowing a lower [Lact]. In line with our results, it has been also reported that sprint training could increase both MCT1 (Bickham et al. 2006; Burgomaster et al. 2007) and MCT4 (Burgomaster et al. 2007) contents, and that high-intensity training sessions seem necessary to obtain high lactate transport capacity (Pilegaard et al. 1994), which support our interpretation.

One other interesting finding in the present study is that only six sessions of intense sprint training induced 
alterations in blood lactate accumulation and net lactate release. In this line, previous data have reported that brief repeated bouts of very intense exercise can rapidly stimulate improvements in muscle oxidative potential (Burgomaster et al. 2005), but also increase MCT content (Burgomaster et al. 2007) since MCT1 and MCT4 belong to a class of proteins can be very rapidly up-regulated (Burgomaster et al. 2007; Coles et al. 2004). Furthermore, these results are in accordance with a previous study on the effects of 4 weeks of endurance training on lactate kinetics parameters (Messonnier et al. 2006), which also reported a reduced muscle lactate accumulation related to a decrease in both the NLRR at the beginning of the recovery and the NALR at 10 min of recovery, and a significant increase in $\mathrm{c}_{2}$. Consistent with these results, Burgomaster et al. (2008) have reported that endurance and sprint training induced similar metabolic adaptations, in particular for oxidative metabolism, but they also observed similar reductions in net muscle glycogenolysis and phosphocreatine degradation during matched-work exercise after both forms of training.

In conclusion, the results of the present study suggested that long-sprint training of short duration reduced metabolic and respiratory perturbations, and allows a 300-m performance improvement, which was also related to intraindividual variations of blood lactate removal ability. In addition, blood lactate accumulation was reduced after training, and was associated with a decrease in the NLRR at the beginning of the recovery and the NALR at $10 \mathrm{~min}$ of recovery after constant exercise test. Although not measured, alterations in glycolytic flux and MCT content are the main hypothesis to explain these lactate metabolism adaptations.

Acknowledgments The authors would like to thank all athletes for their voluntary participation in this study and the athletes' coaches. They also thank Mathieu RABATE and Virha DESPOTOVA for technical assistance and Leslie SEVERINO for English corrections and are grateful to the French Ministry of Health, Youth and Sport for their financial support.

Conflict of interest The authors have no conflict of interest.

\section{References}

Aaron EA et al (1992) Oxygen cost of exercise hypernea: implications for performance. J Appl Physiol 72:1818-1825

Bickham DC et al (2006) The effects of short-term sprint training on MCT expression in moderately endurance-trained runners. Eur $\mathbf{J}$ Appl Physiol 96:636-643

Bret C et al (2003) Differences in lactate exchange and removal abilities in athletes specialised in different track running events (100 to $1500 \mathrm{~m}$ ). Int J Sports Med 24:108-113

Brooks GA (2000) Intra- and extra-cellular lactate shuttles. Med Sci Sports Exerc 32:790-799
Brooks GA (2002) Lactate shuttle - between but not within cells? J Physiol 541:333-334

Burgomaster KA et al (2005) Six sessions of sprint interval training increases muscle oxidative potential and cycle endurance capacity in humans. J Appl Physiol 98:1985-1990

Burgomaster KA et al (2007) Divergent response of metabolite transport proteins in human skeletal muscle after sprint interval training and detraining. Am J Physiol Regul Integr Comp Physiol 292:R1970-R1976

Burgomaster KA et al (2008) Similar metabolic adaptations during exercise after low volume sprint interval and traditional endurance training in humans. J Physiol 586:151-160

Cadefau J et al (1990) Biochemical and histochemical adaptation to sprint training in young athletes. Acta Physiol Scand 140:341-351

Coles L et al (2004) Exercise rapidly increases expression of the monocarboxylate transporters MCT1 and MCT4 in rat muscle. J Physiol 561:253-261

Costill DL et al (1976) Skeletal muscle enzymes and fiber composition in male and female track athletes. J Appl Physiol 40:149-154

Dascombe BJ et al (2007) The reliability of the i-STAT clinical portable analyser. J Sci Med Sport 10:135-140

Davison RC et al (2000) Assessment of blood lactate: practical evaluation of the Biosen 5030 lactate analyzer. Med Sci Sports Exerc 32:243-247

Dawson B et al (1998) Changes in performance, muscle metabolites, enzymes and fibre types after short sprint training. Eur J Appl Physiol Occup Physiol 78:163-169

Dubouchaud $\mathrm{H}$ et al (2000) Endurance training, expression, and physiology of LDH, MCT1, and MCT4 in human skeletal muscle. Am J Physiol Endocrinol Metab 278:E571-E579

Favero TG et al (1995) Metabolic end products inhibit sarcoplasmic reticulum $\mathrm{Ca}$ release and $[3 \mathrm{H}]$ ryanodine binding. J Appl Physiol 78:1665-1672

Fournier M et al (1982) Skeletal muscle adaptation in adolescent boys: sprint and endurance training and detraining. Med Sci Sports Exerc 14:453-456

Freund H, Gendry P (1978) Lactate kinetics after short strenuous exercise in man. Eur J Appl Physiol Occup Physiol 39:123-135

Freund H, Zouloumian P (1981a) Lactate after exercise in man: I. evolution kinetics in arterial blood. Eur J Appl Physiol Occup Physiol 46:121-133

Freund H, Zouloumian P (1981b) Lactate after exercise in man: IV. physiological observations and model predictions. Eur J Appl Physiol Occup Physiol 46:161-176

Hanon C et al (2010) Oxygen uptake and blood metabolic responses to a 400-m run. Eur J Appl Physiol 109:233-240

Harmer AR et al (2000) Skeletal muscle metabolic and ionic adaptations during intense exercise following sprint training in humans. J Appl Physiol 89:1793-1803

Hickson RC et al (1976) Skeletal muscle enzyme alterations after sprint and endurance training. J Appl Physiol 40:868-871

McKenna MJ et al (1997) Enhanced pulmonary and active skeletal muscle gas exchange during intense exercise after sprint training in men. J Physiol 501(Pt 3):703-716

Messonnier L et al (2001) Blood lactate exchange and removal abilities after relative high-intensity exercise: effects of training in normoxia and hypoxia. Eur J Appl Physiol 84:403-412

Messonnier L et al (2006) Effects of training on lactate kinetics parameters and their influence on short high-intensity exercise performance. Int J Sport Med 27:60-66

Messonnier L et al (2007) Importance of $\mathrm{pH}$ regulation and lactate/ $\mathrm{H}$ transport capacity for work production during supramaximal exercise in humans. J Appl Physiol 102:1936-1944 Newsholme

EA et al (1994) 'Keep on running. The science of training and performance.'. Wiley, Chichester 
Nielsen HB et al (2002) Bicarbonate attenuates arterial desaturation during maximal exercise in humans. J Appl Physiol 93: 724-731

Parra J et al (2000) The distribution of rest periods affects performance and adaptations of energy metabolism induced by high-intensity training in human muscle. Acta Physiol Scand 169:157-165

Peronnet $\mathrm{F}$ et al (2007) Bicarbonate infusion and $\mathrm{pH}$ clamp moderately reduce hyperventilation during ramp exercise in humans. J Appl Physiol 102:426-428

Pilegaard $\mathrm{H}$ et al (1994) Lactate transport studied in sarcolemmal giant vesicles from human muscle biopsies: relation to training status. J Appl Physiol 77:1858-1862

Roberts AD et al (1982) Anaerobic muscle enzyme changes after interval training. Int J Sports Med 3:18-21
Rodas $G$ et al (2000) A short training programme for the rapid improvement of both aerobic and anaerobic metabolism. Eur J Appl Physiol 82:480-486

Shepley B et al (1992) Physiological effects of tapering in highly trained athletes. J Appl Physiol 72:706-711

Spriet LL et al (1985) Effects of acidosis on rat muscle metabolism and performance during heavy exercise. Am J Physiol 248:C337-C347

Thomas C et al (2004) Relationships between maximal muscle oxidative capacity and blood lactate removal after supramaximal exercise and fatigue indexes in humans. J Appl Physiol 97:2132-2138

Thomas $\mathrm{C}$ et al (2005) Monocarboxylate transporters, blood lactate removal after supramaximal exercise, and fatigue indexes in humans. J Appl Physiol 98:804-809 